\title{
Inducción de organogénesis in vitro con 6-bencilaminopurina en Cattleya trianae Linden \& Rchb.f.
}

\section{Induction of organogenesis in vitro with 6-benzylaminopurine in Cattleya trianae Linden \& Rchb.f.}

\author{
Arlette Ivonne Gil C.'; César Alfonso Ariza C. ${ }^{2}$; Lina María Castillo T. ${ }^{3}$; Luis Eduardo Salgado D. ${ }^{4}$; \\ Laguandio Banda Sánchez ${ }^{5}$; Luis Eduardo Vanegas M. ${ }^{6}$
}

${ }^{1}$ Ing. Agronómo, M.Sc. Universidad de Cundinamarca, Programa de Ingeniería Agronómica, Grupo de investigación PROSAFIS. Fusagasugá, Cundinamarca, Colombia. e-mail: aigil@ucundinamarca.edu.co; (Dhttps://orcid.org/0000-0001-6536-5877

${ }^{2}$ Ing. Agronómo, M.Sc. Universidad de Cundinamarca, Programa de Ingeniería Agronómica, Grupo de investigación PROSAFIS. Fusagasugá, Cundinamarca, Colombia. e-mail: caariza@ucundinamarca.edu.co; Dhttps://orcid.org/0000-0002-6983-7621

${ }^{3}$ Estudiante de Ingeniería Agronómica. Universidad de Cundinamarca, Programa de Ingeniería Agronómica, Semillero de investigación PROCREDEVE. Fusagasugá, Cundinamarca, Colombia. e-mail: Imariacastillo@ucundinamarca.edu.co; Dhttps://orcid.org/0000-0001-8078-4164

${ }^{4}$ Estudiante de Ingeniería Agronómica. Universidad de Cundinamarca, Programa de Ingeniería Agronómica, Semillero de investigación PROCREDEVE; Fusagasugá, Cundinamarca, Colombia. e-mail: lesalgado@ucundinamarca.edu.co; Dhttps://orcid.org/0000-0002-6795-7646

${ }^{5}$ Ing. Agronómo, M.Sc. Universidad de Cundinamarca, Programa de Ingeniería Agronómica, Grupo de investigación PROSAFIS. Fusagasugá, Cundinamarca, Colombia. e-mail: Ibanda@ucundinamarca.edu.co; Dhttps://orcid.org/0000-0002-3010-9360

${ }^{6}$ Ing. Agrónomo, Esp. Universidad de Cundinamarca, Programa de Ingeniería Agronómica, Grupo de investigación PROSAFIS. Fusagasugá, Cundinamarca, Colombia. e-mail: Ivanegas@ucundinamarca.edu.co; Dhttps://orcid.org/0000-0003-3115-0776

Cómo citar: Gil C., A.I.; Ariza C., C.A.; Castillo T., L.M.; Salgado D., L.E.; Banda Sánchez, L.; Vanegas M., L.E. 2019. Inducción de organogénesis in vitro con 6-bencilaminopurina en Cattleya trianae Linden \& Rchb.f. Rev. U.D.C.A Act. \& Div. Cient. $22(2): e 1275$. https://doi.org/10.31910/rudca.v22.n1.2019.1275

Artículo de acceso abierto publicado por Revista U.D.C.A Actualidad \& Divulgación Científica, bajo una licencia Creative Commons CC BY-NC 4.0

Recibido: Agosto 28 de 2018

Aceptado: Julio 5 de 2019

Editado por: Ingeborg Zenner de Polanía

\section{RESUMEN}

La orquídea Cattleya trianae Linden \& Rchb.f. es reconocida como flor nacional de Colombia y se encuentra en peligro crítico, al presentar una reducción estimada mayor al $80 \%$ en los últimos 100 años, debido a la disminución en la calidad del hábitat y niveles altos de explotación o recolección. La familia Orchidaceae es una de las que mayor número de especies posee en el reino Plantae, con aproximadamente 900 géneros, de los cuales, el 38\% es endémico de Colombia, concentrado en la región Andina, con $87,2 \%$. Esta investigación buscó profundizar en el tema de la propagación como mecanismo de conservación, para lo cual, se determinó el efecto de la 6-Bencilaminopurina (6-BAP), sobre el desarrollo in vitro, en Fusagasugá (Cundinamarca), en un diseño de bloques completamente al azar, con 3 repeticiones. Cuerpos protocórmicos provenientes de semillas recolectadas en Pacho (Cundinamarca) fueron sembrados en medio básico Murashige \& Skoog, enriquecido con 4 concentraciones de 6-BAP. Los resultados mostraron respuestas diferenciales a la adición de la citoquinina, ya que, con la concentración más alta, se obtuvo el mayor porcentaje de callos, con la de $0,05 \mathrm{mg} . \mathrm{L}^{-1}$, el mayor porcentaje de brotes y sin la aplicación del regulador de crecimiento, el mayor porcentaje de raíz. 
Palabras clave: biotecnología; cultivo de tejidos; epífitas; especies en peligro crítico (Tesauro ambiental para Colombia. www.siam. invemar.org.co).

\section{ABSTRACT}

The orchid Cattleya trianae Linden \& Rchb.f. is recognized as the national flower of Colombia, the species is in a critical danger, presenting an estimated reduction of more than $80 \%$ in the last 100 years due to the decrease in habitat quality and high levels of exploitation or harvesting. The Orchidaceae family is one of the largest number of species in the Plant Kingdom, with approximately 900 genera, of which 38\% are endemic in Colombia, concentrated in the Andean region with $87.2 \%$. This research sought to deepen in the topic of the propagation as mechanism of protection for their conservation, for which the effect of cytokinin 6-benzylaminopurine (6-BAP) on development was determined in vitro in Fusagasugá (Cundinamarca), in a completely randomized block design with 3 replicates. The protocorm-like bodies from seeds collected in Pacho (Cundinamarca) were sown in a basic medium Murashige and Skoog enriched with 4 concentrations of 6-BAP. The results showed differential responses to the addition of cytokinin, as the highest concentration was obtained the highest percentage of callus, with the $0.05 \mathrm{mg}$. $\mathrm{L}^{-1}$, the highest percentage of shoots and without the application of the growth regulator, the highest root percentage.

Keywords: biotechnology; tissue culture; epiphytes; critically endangered species.

\section{INTRODUCCIÓN}

El conjunto de plantas de mayor diversidad, a nivel mundial, se encuentra registrado en la familia Orchidaceae, especialmente en los trópicos. Para Colombia, el Ministerio de Ambiente y Desarrollo Sostenible y la Universidad Nacional de Colombia (2015), reportaron 4.270 especies, estableciendo 1.572 de ellas. nativas del país. En los ambientes tropicales, las orquídeas se encuentran en condiciones de alta vulnerabilidad, por el constante saqueo e intervención de los ecosistemas, donde se desarrollan estas plantas. Los hábitats con mayor abundancia de orquídeas son las zonas húmedas y muy húmedas y los países en Latinoamérica con mayor diversidad son Ecuador, Colombia, Brasil y Perú (Rittershausen, 2007).

En Cundinamarca, la biodiversidad de orquídeas está representada en 940 especies, de las cuales, 100 se consideran endémicas y el $51 \%$ del total está bajo alguna categoría de amenaza, que se puede atribuir a la amplia comercialización en Colombia y mercados internacionales, como Alemania, Estados Unidos y Japón (CalderónSáenz, 2007).

Esta inmensa riqueza implica una gran responsabilidad para el país, asumida por el adelanto de esfuerzos en la conservación. Evitar esta pérdida de la biodiversidad es uno de los grandes retos actuales para la humanidad, pues solo ello podrá garantizar la satisfacción de sus necesidades presentes y futuras (Betancur et al. 2015).
Cattleya trianae Linden \& Rchb.f. tiene pocas probabilidades de permanecer en el medio actual de forma natural, debido a la disminución en la calidad del hábitat y niveles altos de explotación o recolección (Castellanos et al. 2017). La evaluación de los ecosistemas del milenio señaló que, aproximadamente, el 60\% de los ecosistemas están siendo degradados o utilizados de forma no sostenible (García et al. 2010).

Una de las condiciones biológicas que limitan la propagación de la mayoría de las orquídeas en ambientes naturales es la de producir semillas muy pequeñas y sin reservas nutricionales para el crecimiento del embrión. Un caso de referencia es el de la orquídea Prosthechea sp. de la zona andina de Fusagasugá-Colombia, donde se reportaron más de tres millones de semillas por cápsula, con un peso estimado de $5,5 \times 10^{-3} \mathrm{~g}$, para 15.000 semillas y la capacidad germinativa fue próxima al 29\%, bajo condiciones in vitro (Banda et al. 2017). Esto conlleva a la necesidad de estandarizar procesos de propagación de orquídeas en ambientes controlados, con el uso herramientas biotecnológicas, como los procesos de propagación in vitro.

Por otro lado, la presencia de un metabolismo ácido de las Crasuláceas (CAM) en las orquídeas y el crecimiento epífito caracterizado por una baja absorción de nutrientes y retención de humedad de la mayoría de estas plantas, son determinantes del lento crecimiento de las orquídeas respecto a otras plantas (Gaudencio Sedano et al. 2015).

Todo lo anterior llevó a la generación de proyectos encaminados al uso de nuevas tecnologías, que aseguren prolongar la existencia de las especies en amenaza. Por ello, los métodos de cultivo in vitro están siendo utilizados con éxito para la conservación y la propagación de especies de orquídeas en peligro de extinción y de importancia medicinal (Deb \& Pongener, 2011).

El uso de la citoquinina 6-Bencilaminopurina (6-BAP) en el cultivo in vitro promueve la proliferación de orquídeas, porque interviene, principalmente, en la división celular, aunque el efecto pudiera variar según el estado de diferenciación de las células, induciendo la formación de órganos (Raven et al. 1992).

Por las anteriores razones, el objetivo de esta investigación fue evaluar el tipo de respuesta de $C$. trianae in vitro, a partir de cuerpos protocórmicos, en medio Murashige \& Skoog (MS), con diferentes concentraciones de la fitohormona 6-BAP para obtener tejidos, como callos, brotes y raíces, con miras a la propagación, como un recurso a mediano plazo, para mitigar la disminución de esta especie en los ecosistemas naturales, propios de la región de Cundinamarca y también como un posible mecanismo para su aprovechamiento comercial.

\section{MATERIALES Y MÉTODOS}

La presente investigación, se llevó a cabo bajo condiciones controladas en las instalaciones del laboratorio de Cultivo de Tejidos Vegetales de la Universidad de Cundinamarca, ubicada en Fusagasugá (Cundinamarca, Colombia), a una altura de $1.687 \mathrm{~m}$ 
s.n.m., temperatura promedio de $25,5 \pm 8^{\circ} \mathrm{C}$ y fotoperiodos de 12 horas de luz y 12 horas de oscuridad, regulados por un temporizador. Se utilizó luz blanca fría provenientes de tubos fluorescentes de $6500 \mathrm{~K}$. El tiempo total de la duración del experimento fue de 180 días, con períodos de evaluación de 30 días.

Material vegetal. Se utilizaron cuerpos protocórmicos procedentes de semillas de C. trianae (Figura 1), cultivados in vitro de 90 a 120 días, en medio Charcoal Orchid Maintenance $\AA$, en la estación Chilacas, en Pacho (Cundinamarca), a una altura de $2.050 \mathrm{~m}$ s.n.m., temperatura promedia de $17^{\circ} \mathrm{C}$ y humedad relativa promedia de $85 \%$, bajo luz blanca fría. Posteriormente, fueron trasladadas en nevera de icopor a Fusagasugá (Cundinamarca), para realizar las pruebas de laboratorio.
Medio de cultivo. Los cuerpos protocórmicos fueron subcultivados sobre medio básico Murashige \& Skoog (MS) (1962), suplementado con 30g. $\mathrm{L}^{-1}$ de sacarosa, 6g. $\mathrm{L}^{-1}$ de agar y cuatro diferentes concentraciones de 6-BAP $\left(0 ; 0,05 ; 0,5\right.$ y $\left.2 \mathrm{mg} \cdot \mathrm{L}^{-1}\right)$. El pH del medio fue ajustado a 5,8 antes de la esterilización. El medio fue esterilizado en autoclave a $121^{\circ} \mathrm{C}$ y 15 PSI por 20 minutos.

El subcultivo de los cuerpos protocórmicos fue realizado en condiciones asépticas, en frascos de $250 \mathrm{cc}$, que contenían $20 \mathrm{~mL}$ del medio básico MS. Tres cuerpos protocórmicos de tamaño similar fueron colocados por frasco de forma equidistante.

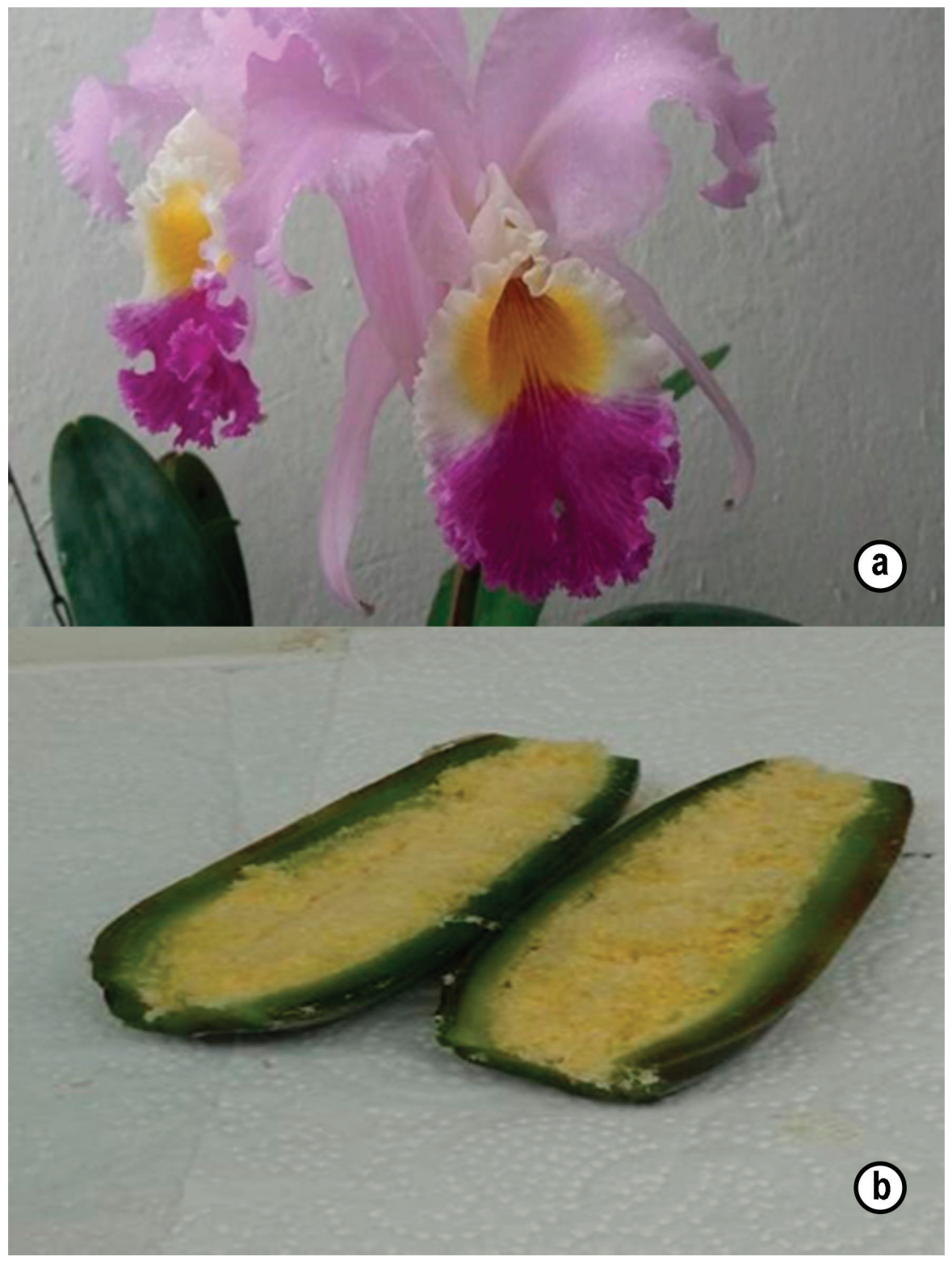

Figura 1. Cattleya trianae a. Ejemplar florecido; b. Cápsula con numerosas semillas. 
Diseño experimental. Se utilizó un diseño de bloques completos al azar con tres repeticiones, donde el factor de bloqueo correspondió al tamaño inicial de los cuerpos protocórmicos. Cada repetición y cada bloque se conformó por 10 frascos de vidrio de 250cc, con 20mLde medio sólido.

Variables evaluadas. Se evaluó el porcentaje de distintos tipos de respuesta in vitro (callo, formación de láminas foliares y formación de raíces), a partir de los 90 días después de la siembra. El porcentaje de estructuras (n) de callos, brotes y raíces formadas, se determinó mediante la relación: porcentaje $(\%)$ de $\mathrm{n}=[$ (número de explantes con estructura formada) / (número total de explantes sembrados)] $\mathrm{x} 100$

Análisis estadístico. Los porcentajes de formación de callo, formación de lámina foliar y formación de raíz fueron analizados mediante análisis de varianza y se determinaron las diferencias entre los tratamientos por medio de la prueba de comparación de medias LSD Fischer al 5\% de significancia. Además, se determinó el coeficiente de correlación no paramétrico de Spearman (rs) (Martínez et al. 2009) entre las variables evaluadas, con el fin de determinar si existía relación entre ellas. Los anteriores análisis, se realizaron utilizando el programa Infostat 2017 (Di Rienzo et al. 2017).

\section{RESULTADOS Y DISCUSIÓN}

En el experimento desarrollado, se evidenció la formación de tejidos diferenciados y tejidos sin diferenciar a los 90 días, después de la siembra del material vegetal. Según Cedrés Gazo et al. (2015), los explantes establecidos in vitro pueden tener el crecimiento indiferenciado, que genera una masa de células no diferenciadas, denominada callo o, diferenciado, que forman tejidos, dando lugar a brotes y raíces. En $C$. trianae, la organogénesis directa, que originó brote y raíz e, indirecta, formadora de callo, fueron respuestas comunes en el medio MS, que presentaron variaciones en los porcentajes de respuesta con el uso 6-BAP (Figura 2).

Inducción de callo. Cuando se utilizó la citoquinina en concentración de $2 \mathrm{mg} \cdot \mathrm{L}^{-1}$ de 6-BAP (Figura 3), se obtuvo el mayor porcentaje de callos, con un 29,1\%, mostrando diferencias estadísticas con respecto a las demás concentraciones. Castellanos \& Torres (2018) indican que la formación de cuerpos protocórmicos de $C$. trianae se ve influenciada por la temperatura ambiental, ya que se requieren de temperaturas diurnas, aproximadas de $26^{\circ} \mathrm{C}$ y nocturnas, de $18^{\circ} \mathrm{C} \mathrm{o}$, en promedio, de $20^{\circ} \mathrm{C}$, en la fase de multiplicación.

La no aplicación del regulador de crecimiento en los ensayos estimuló en 13,7\% la formación de callos, lo que se atribuye con la totipotencia que presenta el material, desde el punto de vista morfogénico.

Cabe resaltar que los callos obtenidos con el tratamiento de $2 \mathrm{mg} \cdot \mathrm{L}^{-1}$ de 6-BAP no tuvieron la capacidad de generar nuevos órganos, lo que concuerda con los resultados obtenidos por Caetano et al. (2011), en explantes de pitahaya amarilla (Selenicereus megalanthus (K. Schum. ex Vaupel) Moran), quienes obtuvieron callos no regenerantes, con el uso de citoquininas, debido a factores ambientales; el BAP, se aplicó en dosis iguales de $2.21 \mu \mathrm{M}$, combinado con 2,4-D (Ácido 2,4-diclorofenoxiacético) y TDZ (Thidiazuron) en medio MS (Murashige y Skoog). En ocasiones, el tipo de callo obtenido, así como el grado de diferenciación celular y su capacidad de regeneración a nuevas plántulas, dependen del origen y la edad del tejido elegido como explante (Gätjens et al. 2018).

Resultados similares fueron obtenidos en investigaciones con la orquídea Laelia anceps ssp. dawsonii, donde a partir de semillas se indujo callo embriogénico en medio MS. La combinación Ácido Naftalenacético (ANA)+6-Bencilaminopurina (6-BAP)+Ácido Indolacético (AIA) (2mg. $\mathrm{L}^{-1}$ de cada una) resultó óptima para inducción de callo, pues produjo 611 embriones somáticos en fotoperiodo de 16 horas y, además, los embriones desarrollaron plántulas completas (Lee Espinoza et al. 2010). En otra investigación bajo condiciones in vitro con la orquídea Prosthechea sp. en Fusagasugá (Cundinamarca, Colombia), usando ácido naftalenacético (ANA), se estimuló la regeneración secundaria de protocormos, adicionando al medio básico de cultivo $1,5 \mathrm{mg} \cdot \mathrm{L}^{-1}$ de ANA y se promovió, inicialmente, la formación de callo (Gil et al. 2016). Este tipo de trabajos orientan en el proceso de optimización y pertinencia con el uso de fitohormonas sobre la propagación controlada de orquídeas, como fue el objeto de la presente investigación.

En estudios realizados por Ávila-Díaz \& Salgado-Garciglia (2006) en orquídeas, se encontró que la adición de reguladores de crecimiento, como auxinas, citoquininas y giberelinas, no siempre favorece la estimulación del desarrollo de vitroplantas, debido a que se puede presentar la aparición y el aumento del desarrollo de callogénesis, lo cual, está directamente relacionado con una disminución del crecimiento, principalmente, a nivel del rizoma. Los factores más importantes para lograrlo son el genotipo, la composición del medio de cultivo, así como la concentración del regulador de crecimiento (Aloísio, 1997).

Rivero-Bautista et al. (2008) afirman que el color, la forma y la apariencia del callo con estructuras morfogénicas varía entre los genotipos, lo que depende del medio de cultivo utilizado, indicando que la formación de callos está influenciada por las características propias del explante como la edad, el tamaño, la procedencia y el genotipo.

Se puede concluir que al adicionar 6-BAP en la mayor concentración al medio básico de cultivo, se promovió la mayor producción de callos, lo cual, indica su relación con la organogénesis indirecta en esta especie.

Desarrollo de brotes. Como se observa en la figura 4, cuando $C$. trianae se desarrolló en el medio básico suplementado con 0,05mg.. $\mathrm{L}^{-1}$ de 6-BAP, se obtuvo un $47,2 \%$ de brotes, mientras que al prescindir del regulador de crecimiento, disminuyó a un 33,5\%, mostrando diferencias estadísticas entre estos dos tratamientos. 


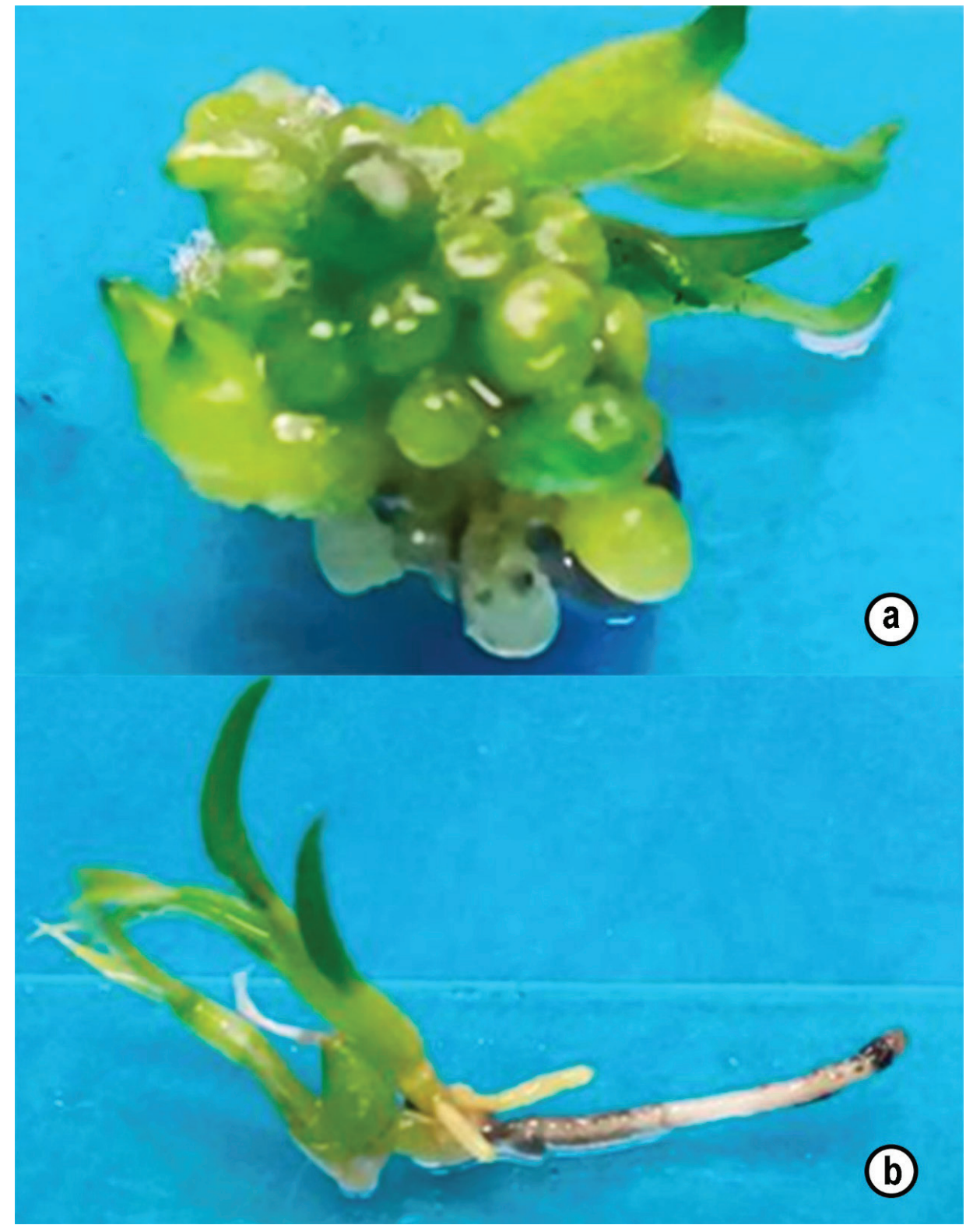

Figura 2. Cattleya trianae bajo condiciones de propagación in vitro. a. callo; b. brote. 


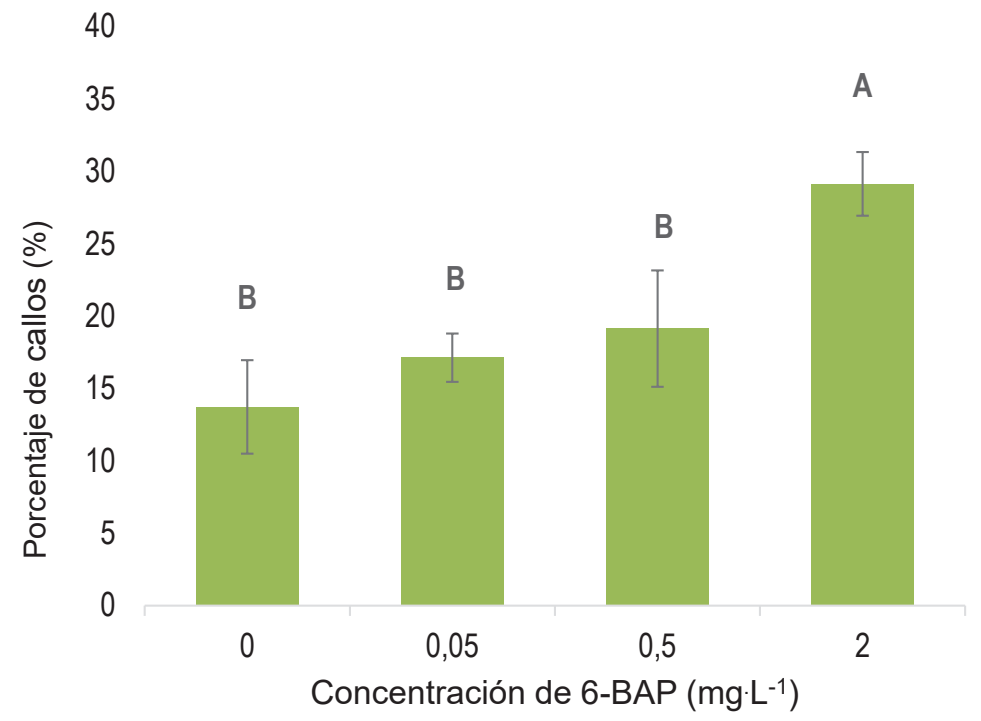

Figura 3. Proliferación de callos (\%) de Cattleya trianae bajo concentraciones de 6-BAP in vitro. Valores con letras diferentes difieren estadísticamente para $\mathrm{P} \leq 0,05$.

60

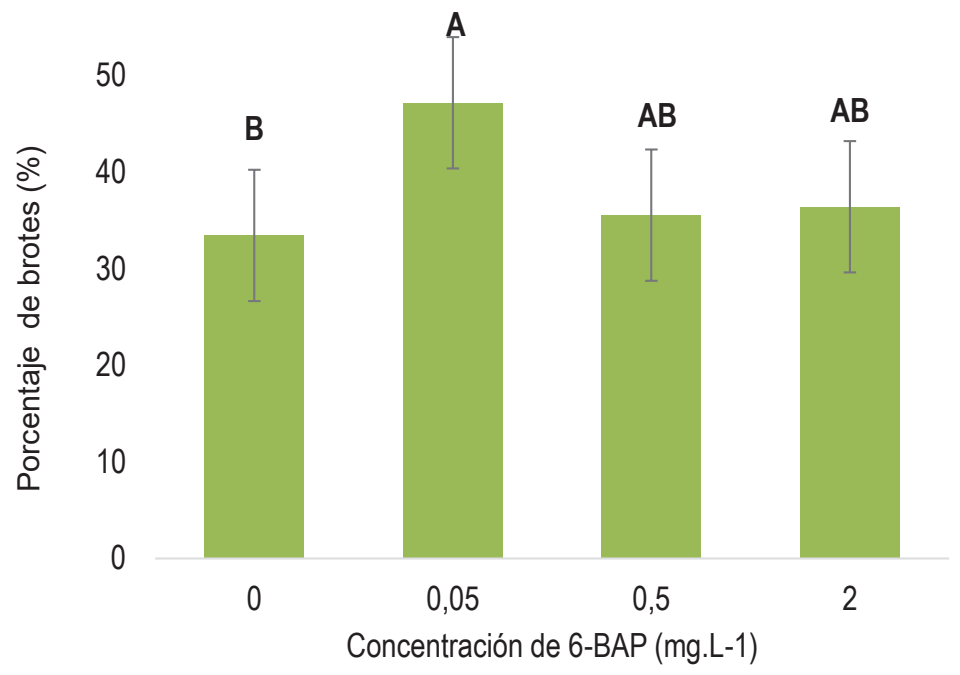

Figura 4. Respuesta de brotes (\%) en condiciones in vitro con 6-BAP en Cattleya trianae. Valores con letras diferentes difieren estadísticamente para $\mathrm{P} \leq 0,05$.

Este resultado concuerda con la investigación desarrollada por Cazarez Favela et al. (2016) con la orquídea Prosthechea citrina (La Llave \& Lex.) W. E. Higgins, quienes evidenciaron en la fase de organogénesis que, al agregar 6-BAP al medio de cultivo en concentraciones de 1 a $3 \mathrm{mg} \cdot \mathrm{L}^{-1}$, se logró el proceso de brotación, obteniendo un promedio de 6,75 brotes por explante. Lo anterior evidencia la relación directa de las citoquininas sobre la caulogénesis en $C$. trianae, bajo condiciones in vitro.
Proliferación de raíces. El uso de 6-BAP en las mayores concentraciones, de 0,5 y $2 \mathrm{mg} \cdot \mathrm{L}^{-1}$, disminuyó la formación de raíces en $C$. trianae, con un $0,62 \%$ y $0,56 \%$, respectivamente, tal como se aprecia en la figura 5. La no utilización de la citoquinina en el medio básico de cultivo reportó el mayor valor, con un 7,35\%, a diferencia de los resultados de Borges García et al. (2011), quienes evidenciaron en Dioscorea alata que los niveles de 0,01 y $0,1 \mathrm{mg} \cdot \mathrm{L}^{-1}$ de ANA y la más baja, combinación de ANA/ 6-BAP, de 0,01 y 0,01 mg.L $\mathrm{L}^{-1}$, fueron los más adecuados para estimular el enraizamiento y la formación de 


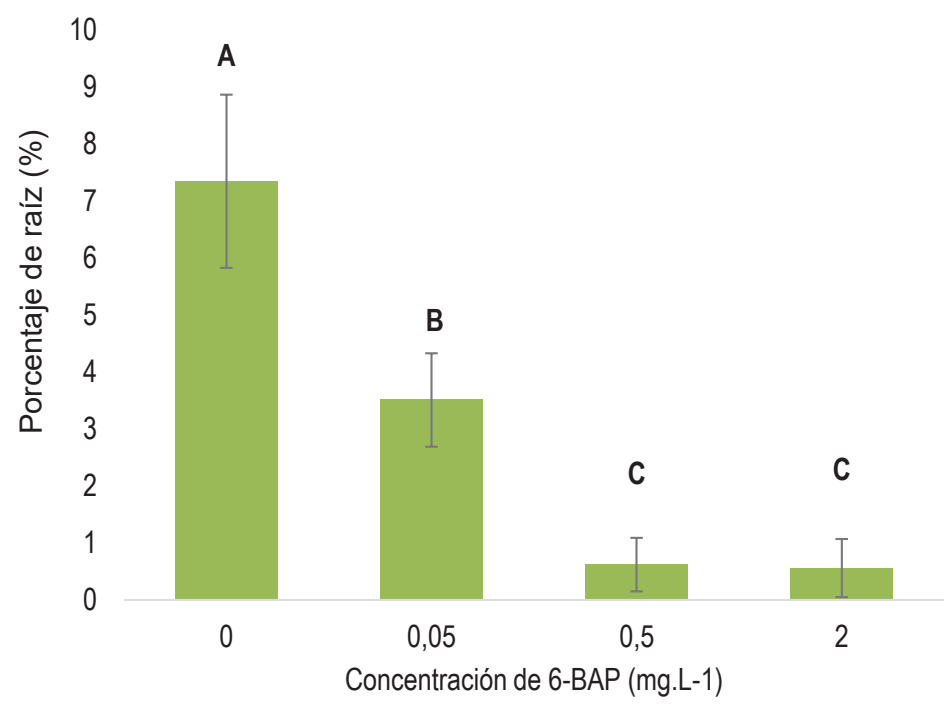

Figura 5. Enraizamiento (\%) de Cattleya trianae con 6-BAP. Valores con letras diferentes difieren estadísticamente para $\mathrm{P} \leq 0,05$.

nuevas raíces, a diferencia de este estudio, en donde únicamente se utilizó 6-BAP y ninguna auxina.

En investigaciones realizadas en Cattleya máxima y Cattleya rex por Villanueva et al. (2013), empleando el medio base Murashige \& Skoog con los reguladores de crecimiento giberelina $\left(0,031 \mathrm{~g} . \mathrm{L}^{-1}\right), 6-\mathrm{BAP}$ $\left(0,083 \mathrm{~g} \cdot \mathrm{L}^{-1}\right)$ y ANA $\left(0,031 \mathrm{~g} \cdot \mathrm{L}^{-1}\right)$, se favoreció la inducción de la germinación in vitro de las semillas crecimiento de los protocormos, multiplicación y enraizamiento de plántulas.

En la orquídea Encyclia microtos (Rchb.f.) Hoehne con 6-BAP, a concentraciones de $2 \mathrm{mg} \cdot \mathrm{L}^{-1}$ y combinados Ácido Indolbutírico (IBA) (2mg.L $\left.\mathrm{L}^{-1}\right)$ con 6-BAP (2mg. $\left.\mathrm{L}^{-1}\right)$, se promovió el mayor desarrollo de yemas axilares, obteniéndose una tasa de multiplicación del doble de plántulas y 1,8 plántulas, respectivamente (Condemarín-Montealegre et al. 2007).

Valderrama Alfaro et al. (2009) evaluaron el medio basal Knudson suplementado con 0,5\% de carbón activado y $4 \mathrm{mg} . \mathrm{L}^{-1}$ de 6-BAP, sobre el desarrollo in vitro de la orquídea Epidendrum sp., encontrando que se favoreció el desarrollo de raíces, protocormos y yemas axilares en plántulas, obteniendo $75 \%$ de plántulas con formación de yemas axilares, 45\% de plántulas enraizadas, 17\% de plántulas con desarrollo de protocormos y $8 \%$ de plántulas con formación de raíces y protocormos a la vez.

El 6-BAP también favorece la formación de protocormos, según resultados obtenidos en la orquídea Chloraea crispa, con una concentración de $0,1 \mathrm{mg} . \mathrm{L}^{-1}$ bajo condiciones de oscuridad, de acuerdo con Quiroz et al. (2017).
En esta investigación, los tratamientos con citoquinina aumentaron la respuesta de brotes y disminuyeron la formación de raíces, según lo propuesto por Skoog \& Miller (1957), en una serie clásica de experimentos, donde demostraron que la relación de citoquinina/auxina en los medios nutritivos influye profundamente en la morfogénesis de las raíces y los brotes en el cultivo de tejidos vegetales.

Todo proceso de diferenciación está regulado por el balance entre auxinas y citoquininas: para la formación de raíces deben prevalecer las auxinas, mientras que las citoquininas conducirán a la formación del vástago de la planta (Eckardt, 2003), con lo cual, se corrobora el modelo de organogénesis.

Los resultados de este estudio mostraron que la inducción de callos y brotes se vio favorecida hasta en un 15,4 y $13,7 \%$, respectivamente, al aplicar 6-BAP con respecto al control, en contraste con el enraizamiento, que fue hasta un 6,8\% superior al no aplicar el regulador de crecimiento vegetal.

Basados en los resultados de la presente investigación, se recomienda utilizar los procesos de propagación in vitro de manera masiva, no solo para C. trianae sino en general, para la mayoría de las especies de orquídeas, como una herramienta de conservación en especies con alto riesgo de amenaza, en concordancia con lo expuesto en la investigación realizada por Salazar Mercado \& Vega Contreras (2017) $\mathrm{y}$, adicionalmente, también se podría pensar como un mecanismo para su posterior empleo, con fines de comercialización.

Agradecimientos: A la empresa GEOAMBIENTE-SAS, por su colaboración para el desarrollo de esta investigación. Conflicto de 
intereses: El presente manuscrito fue preparado y revisado con la participación de todos los autores, quienes declaramos que no existe conflicto de intereses que ponga en riesgo la validez de los resultados presentados. Financiación: Esta investigación fue financiada por la Universidad de Cundinamarca.

\section{REFERENCIAS}

1. ALOÍSIO, X. 1997. Enraizamiento in vitro de gemas de Eucalyptus multiplicados e alongados. Scientia Forestalis (Brasil). 51:26-29.

2. ÁVILA-DÍAZ, I.; SALGADO-GARCIGLIA, R. 2006. Propagación y mantenimiento in vitro de orquídeas mexicanas, para colaborar en su conservación. Revista Biológicas. 8:138-149.

3. BANDA, L.; PINZÓN, Y.; VANEGAS, L. 2017. Características físicas y germinativas de semillas de la orquídea Prosthechea sp. de la zona andina, Fusagasugá, Colombia. Biota Colombiana. 18(1):80-87. https://doi.org/10.21068/ c2017.v18n01a6

4. BETANCUR, J.; SARMIENTO, H.; TORO-GONZÁLEZ, L.; VALENCIA, J. 2015. Plan para el estudio y la Conservación de las Orquídeas en Colombia [Recurso Electrónico] /Textos: Universidad Nacional De Colombia. Facultad De Ciencias. Instituto De Ciencias Naturales; Coord. Técnica: Higuera Díaz, Diego Minambiente. Dirección de Bosques, Biodiversidad y Servicios. 336p.

5. BORGES GARCÍA, M.; DESTRADE BATISTA, R.; MENESES RODRÍGUEZ, S.; GÓMEZ KOSKY, R.; MALAURIE, B.; HAMON, P.; DEMENORVAL, L.C. 2011. Optimización de un medio de cultivo para plantas micropropagadas de Dioscorea alata L. Rev. Col. Biotecnología. 13(2):221-228.

6. CAETANO, C.; OTÁllVARO, F.; MUÑOZ, J.; MORALES, J.; SUÁREZ, R.; SANDOVAL, C.; MARTÍNEZ, M.; CAÑAR, D.; PEÑA, R.; PARRA, E.; GALÍNDEZ, E.; ROJAS, R.; JIMÉNEZ, J.; BENAVIDES, A.; PÉREZ, L. 2011. Enfoque multidisciplinario para solución en el agro colombiano: El caso Pitahaya amarilla Selenicereus megalanthus. Rev. Asoc. Col. Cienc. 23(3):52-64.

7. CALDERÓN-SÁENZ, E. 2007. Libro Rojo de Plantas de Colombia. Volumen 6: Orquídeas, Primera Parte. Serie Libros Rojos de Especies Amenazadas de Colombia. Bogotá: Instituto Alexander von Humboldt. Ministerio de Ambiente, Vivienda y Desarrollo Territorial. 820p.

8. CASTELLANOS, C.; CASTRO, C.; RIVERA, Y.; VALLEJO, M.; LÓPEZ, Y.; LARA, D. 2017. Diversidad de orquídeas en Cundinamarca. Una oportunidad para su aprovechamiento sostenible. En: Moreno, L.A.; Andrade, G.I.; Ruiz-Contreras, L.F. (eds.). Biodiversidad 2016. Estado y tendencias de la biodiversidad continental de Colombia. Instituto de Investigación de Recursos Biológicos Alexander von Humboldt. Bogotá, D. C., Colombia. https://doi.org/10.21068/B001.2016.401

9. CASTELLANOS-CASTRO, C.; TORRES-MORALES, G. 2018. Capítulo 3: Protocolos de propagación para algunas especies de orquídeas nativas de Cundinamarca. En: Guía para la identificación y el cultivo de algunas especies de orquídeas nativas de Cundinamarca. Pontificia Universidad Javeriana, Jardín Botánico de Bogotá "José Celestino Mutis", Corporación Colombiana de Investigación Agropecuaria Corpoica, Instituto de Investigación de Recursos Biológicos Alexander von Humboldt, Gobernación de Cundinamarca. Bogotá D.C., Colombia. 192p.

10. CAZAREZ FAVELA, T.; GRACIANO LUNA, J.; SOLÍS GONZÁLEZ, S.; DÍAZ RAMÍREZ, B.; NÁJERA LUNA, J.; MONTOYA AYÓN, J. 2016. Propagación in vitro de la orquídea Prosthechea citrina (La Llave \& Lex.) W. E. Higgins nativa del estado de Durango, México. Investigación y Ciencia (México). 24(67):19-25.

11. CEDRÉS GAZO, M.; SHARRY, S.; ADEMA, M.; ABEDINI, W. 2015. Plantas de probeta: manual para la propagación de plantas por cultivo de tejidos in vitro. Universidad Nacional de La Plata (Buenos Aires, Argentina). Disponible desde Internet en: http://sedici.unlp.edu. ar/bitstream/handle/10915/46738/Documento_ completo__.pdf-PDFA.pdf?sequence $=1$

12. CONDEMARÍN-MONTEALEGRE, C.; CHICO-RUÍZ, J.; VARGAS-ARTAEGA, C. 2007. Efecto del ácido indol butírico (IBA) y 6-bencilaminopurina (BAP) en el desarrollo in vitro de yemas axilares de Encyclia microtos (Rchb.f.) Hoehne (Orchidaceae). Lankesteriana Internal J. Orchidology (Costa Rica). 7(1-2):247-254. https://doi. org/10.15517/lank.v7i1-2.19513

13. DEB, C.; PONGENER, A. 2011. Asymbiotic seed germination and in vitro seedling development of Cymbidium aloifolium (L.) Sw.: a multipurpose orchid. J. Plant Biochem. Biotechnol. (India). 20(1):90-95. https://doi. org/10.1007/s13562-010-0031-4

14. DI RIENZO, J.A.; CASANOVES, F.; BALZARINI, M.G.; GONZÁLEZ, L.; TABLADA, M.; ROBLEDO, C.W. 2017. InfoStat versión 2017. Grupo InfoStat, FCA, Universidad Nacional de Córdoba, Argentina. Disponible desde Internet en: http://www.infostat.com.ar (con acceso el 24/05/2018). 
15. ECKARDT, N.A. 2003. A new classic of cytokinin research: cytokinin-deficient Arabidopsis plants provide new insights into cytokinin biology. The Plant Cell (USA). 15(11):2489-2492. https://doi.org/10.1105/tpc.151110

16. GARCÍA, H.; MORENO, L.A.; LONDOÑO, C.; SAFRONY, C. 2010. Estrategia nacional para la conservación de plantas: actualización de los antecedentes normativos y políticos y revisión de avances. Instituto de Investigación de Recursos Biológicos Alexander von Humboldt \& Red Nacional de Jardines Botánicos, Bogotá. 160 p.

17. GÄTJENS-BONICHE, O.; ACUÑA-MATAMOROS, C.L.; MONTERO-CARMONA, W.; DÍAZ, C.; TORRES, S. 2018. Propagación masiva y formación de callos protocórmicos de vainilla a partir de ápices radicales. Polibotánica (México). 45:157-180. http://dx.doi. org $/ 10.18387 /$ polibotanica.45.12

18. GAUDENCIO SEDANO, C.; MANZO, A.G.; ROLDÁN, R.H.; CASTELLANOS, S.J. 2015. Propagación in vitro de orquídeas y otras ornamentales. Revista Mexicana de Ciencias Agrícolas. 1:451-456.

19. GIL, A.; CONTRERAS, D.; GUTIÉRREZ, L. 2016. Establecimiento in vitro de protocormos de Prosthechea sp. bajo diferentes concentraciones de ácido naftalenacético. Revista Mutis (Colombia). 6(1):6-15. https://doi. org/10.21789/22561498.1108

20. LEE ESPINOSA, H.E.; LAGUNA CERDA, A.; MURGUÍA GONZÁLEZ, J.; IGLESIAS-ANDREU, L.; GARCÍA ROSAS, B.; ESCOBEDO LÓPEZ, D.; MARTÍNEZ OCAMPO, Y.M.; BARREDO POOL, F.A.; SANTANA BUZZY, N. 2010. Un protocolo de embriogénesis somática para la regeneración y caracterización in vitro de Laelia anceps ssp. dawsonii. Fitotecnia mexicana. 33(4):323332

21. MARTÍNEZ ORTEGA, R.M.; PENDÁS, T.; LEONEL, C.; MARTÍNEZ ORTEGA, M.; PÉREZ ABREU, A.; CÁNOVAS, A.M. 2009. El coeficiente de correlación de los rangos de Spearman caracterización. Rev. Habanera de Ciencias Médicas (Cuba). 8(2):1-19.

22. MINISTERIO DE AMBIENTE Y DESARROLLO SOSTENIBLE Y UNIVERSIDAD NACIONAL DE COLOMBIA. 2015. Plan para el estudio y la conservación de las orquídeas en Colombia. Textos: Betancur, J.; Sarmiento-L., H.; Toro-González, L.; Valencia, J. Ministerio de Ambiente y Desarrollo Sostenible, Colombia; Universidad Nacional de Colombia, Bogotá D.C. $32 p$.
23. MURASHIGE, T.; SKOOG, F. 1962. A revised medium for rapid growth and bioassay with tobacco tissue cultures. Physiologia Plantarum (Suecia). 15:473-497. https:/ / doi. org/10.1111/j.1399-3054.1962.tb08052.x

24. QUIROZ, K.; SAAVEDRA, J.; VOGEL, H.; VERDUGO, G.; CALIGARI, P.D.S.; GARCÍA-GONZÁLES, R. 2017. In vitro asymbiotic germination for micropropagation of the recalcitrant terrestrial orchid Chloraea crispa (Orchidaceae). Applications in Plant Sciences (USA). 5(8):1-9. https:// doi.org/10.3732/apps.1600142

25. RAVEN, P.H.; VERT, R.F; EICHORN, S.E. 1992. Biología de las Plantas. Ed. Reverté. (España). 402p.

26. RITTERSHAUSEN, W.B. 2007. Orquídeas. Ed. Blume (España). 304p.

27. RIVERO-BAUTISTA, N.; AGRAMONTE-PEÑALVER, D.; BARBÓN-RODRÍGUEZ, R.; CAMACHO-CHIU, W.; COLLADO-LÓPEZ, R.; JIMÉNEZ-TERRY, F.; PÉREZ-PERALTA, M.; GUTIÉRREZ-MARTÍNEZ, O. 2008. Embriogénesis somática en (Anthurium andraeanum Lind.) variedad 'Lambada'. Ra Ximhai. 4(1):135-149. https://doi.org/10.35197/rx.04.01.2008.08.nr

28. SALAZAR MERCADO, S.A.; VEGA CONTRERAS, N.A. 2017. Germinación asimbiótica de semillas y propagación in vitro de Cattleya trianae Linden y Reichb.f. (Orchidaceae). Acta Agronómica. 66(4):544-548. https://doi. org/10.15446/acag.v66n4.63597

29. SKOOG, F.; MILLER, C.O. 1957. Chemical regulation of growth and organ formation in plant tissue cultures in vitro. Symp. Soc. Exp. Biol. 11:118-131.

30. VALDERRAMA ALFARO, S.; TEJADA-CASTILLO, P.; SÁNCHEZ MARÍN, R.; PARIMANGO-QUISPE, C; SANTA MARÍA-REYES, A.; VEGA-HUAMÁN, A.; CHICO-RUIZ, J. 2009. Desarrollo in vitro de plántulas de Epidendrum sp. (Orchidaceae) utilizando carbón activado y 6-bencil-amino purina (BAP). REBIOL (Perú). 29(1):15 .

31. VILLANUEVA, C.E.; ARELLANO, C.; SÁNCHEZ, O.; FLORES, C.R. 2013. Adaptación, micropropagación y conservación de orquídeas (Cattleya sp.) nativas de clima tropical húmedo lluvioso. Centro de Biotecnología (Perú). 2(1):52-59. 